\title{
Poder de Mercado no Varejo Alimentar: uma análise usando os preços do estado de São Paulo
}

\author{
Danilo R. D. Aguiar ${ }^{1}$ \\ Adelson Martins Figueiredo ${ }^{2}$
}

Resumo: O setor varejista brasileiro tem apresentado expressivas transformações em sua organização estrutural desde a década de 1990. Se, por um lado, o mercado se mostra bastante concentrado, por outro, há evidências de uma crescente rivalidade entre as empresas. Esta pesquisa objetivou examinar o impacto da concentração de mercado sobre o uso de poder de mercado para produtos agrícolas específicos, por meio de análise de séries temporais dos preços do estado de São Paulo. Os resultados indicaram que o uso de poder de mercado difere de produto para produto, o que indica que os varejistas podem estar adotando estratégias de preços baseadas nas características da demanda dos produtos. A análise da assimetria mostrou que os varejistas tendem a retardar a transmissão de decréscimos de preços, transmitindo mais rapidamente os acréscimos. Os resultados sugerem também que o aumento da rivalidade na presente década tem dificultado o exercício de poder de mercado via preços. Em geral, os varejistas conseguiam repassar mais intensamente os acréscimos de preços no período anterior ao ano 2000, quando a taxa de turnover era menor e este processo se restringia às firmas médias e pequenas.

Palavras-chave: Poder de mercado, Mercado varejista, Concentração de mercado.

Abstract: The Brazilian retail sector has gone through expressive structural transformations since the 90's decade. Despite the high level of concentration, the retail sector has presented evidences of strong rivalry among the top firms. This research aimed to analize the impact of market concentration on the use of market power for specific

1 Professor associado do Departamento de Economia da Universidade Federal de São Carlos, campus de Sorocaba, e bolsista de Produtividade de Pesquisa do CNPq. E-mail: danilo@ufscar.br

2 Professor adjunto do Departamento de Economia da Universidade Federal de São Carlos, campus de Sorocaba. E-mail: adelson@ufscar.br 
agricultural products, through time series analysis of agricultural prices referring to the São Paulo state. The empirical results indicated that the use of market power differs from product to product, what suggests that retailers have been adopting specific strategies according to the characteristics of products demand. The analysis of price asymmetry showed that retailers tend to delay the transmission of price decreases and transmit price increases more rapidly. Moreover, results indicate that the increase in rivalry in the current decade has made it more difficult for retailers to use their market power manipulating prices. In general, retailers were able to transmit price increases more intensely before the year 2000, when the turnover level was lower and restricted to the small and middle size firms.

Key-words: market power, retail market, market concentration.

Classificação JEL: Q13.

\section{Introdução}

Estimativas de indicadores estruturais do mercado varejista brasileiro, realizadas por Aguiar (2009), permitem identificar dois períodos com padrões bastante distintos: período I (de 1994 a 1999), caracterizado por um expressivo aumento da concentração do mercado (com o CR5 atingindo aproximadamente 40\%) e pela liderança do Carrefour; e período II (de 2000 a 2008), onde se observa certa estabilidade na concentração das cinco maiores firmas (com o CR5 mantendo-se ao redor de 40\%) e aumento da participação das três maiores, notando-se ainda elevado nível de turnover no grupo das cinco maiores empresas. Neste segundo período, predominou a liderança por parte da $C B D$, seguida pelo Carrefour, mas, após 2004, verifica-se uma liderança tripla (triopólio) dividida entre CBD, Carrefour e Wal-Mart, com os líderes trocando de posição ano após ano.

Assim, a estrutura do mercado varejista tem ficado mais concentrada, o que favorece o uso de poder de mercado, mas há também sinais de aumento da rivalidade entre as firmas, o que pode limitar o uso do poder de mercado por receio de perda de mercado.

Vários estudos internacionais têm sido desenvolvidos para testar o que é conhecido como trade-off entre poder de mercado e eficiência econômica na indústria e no varejo alimentar ${ }^{3}$, os quais não têm apresentado resultados conclusivos. Estudos recentemente desenvolvidos nos Estados Unidos, por Sharkey e Stiegert (2006) e por Arnade et al. (2007), encontraram suporte para

3 Ver, por exemplo, Lopez et al. (2002) e Lopez e Lirón-España (2003). 
a hipótese de ganho de poder de mercado no setor varejista, enquanto que Cleary e Lopez (2007) verificaram que a entrada do Wal-Mart em mercados locais, também nos Estados Unidos, reduziu o poder de mercado cooperativo dos supermercados ali estabelecidos e promoveu uma tendência de preços decrescentes.

No Brasil, os poucos estudos realizados no início deste século não chegaram a resultados conclusivos. Por exemplo, enquanto Farina e Nunes (2002) não encontraram evidências de manifestação de poder de mercado no setor varejista alimentar brasileiro, Aguiar e Silva (2002) e Cunha e Machado (2003) encontraram suporte para a hipótese de exercício de poder de mercado. Nota-se, porém, que estes estudos diferem quanto ao grau de agregação dos dados utilizados, pois Farina e Nunes analisaram vários índices agregados para o Brasil e para São Paulo, ao passo que Aguiar e Silva analisaram um único produto e Cunha e Machado analisaram, separadamente, supermercados grandes e pequenos em um mesmo mercado local. Os diferentes resultados encontrados por esses autores permitem levantar a hipótese de que é mais provável a identificação de poder de mercado utilizando-se dados mais desagregados, pois nem todas as firmas conseguiriam exercer poder de mercado, assim como o poder de mercado não seria exercido para todos os produtos. Evidências neste sentido foram encontradas por Aguiar (2009), uma vez que este autor não encontrou evidências de uso de poder de mercado ao analisar índices agregados de desempenho.

Considerando-se os resultados divergentes encontrados na literatura, o presente trabalho pretende trazer evidências maiores sobre o impacto da concentração de mercado no exercício de poder de mercado de produtos agrícolas específicos, por meio de análise de séries temporais dos preços em níveis de produtor, atacado e varejo.

\section{Referencial teórico}

A constatação de que o máximo de bem-estar social seria alcançado num mercado perfeitamente competitivo, enquanto o monopólio restringiria o nível de bem-estar da sociedade levou Mason (1939) a delinear um modelo para explicar o relacionamento entre estrutura de mercado, conduta empresarial e desempenho econômico.

A proposição do modelo estrutura-conduta-desempenho (ECD) é de que a estrutura de mercado determinaria a conduta das empresas, e esta determinaria o desempenho do mercado. Embora este sentido de causalidade seja o predominante, as condutas das empresas e o desempenho do mercado também podem afetar a estrutura de mercado, por meio de condutas estratégicas e por meio da lucratividade do setor, respectivamente. Dessa forma, o modelo 
ECD admite um intervalo contínuo entre as estruturas de competição perfeita e monopólio, de maneira que, quanto mais a estrutura de um mercado se aproximasse do monopólio, pior seria seu desempenho, ocorrendo o inverso caso a estrutura do mercado se aproximasse da competição perfeita.

As relações de causa e efeito definidas no modelo ECD têm sido fontes de grandes debates entre os estudiosos de organização industrial. Havendo essa relação causal da estrutura para a conduta, e desta para o desempenho, a melhor maneira de se obter um desempenho satisfatório por parte de um mercado seria por meio de intervenções do governo em sua estrutura. Contrapondo-se aos economistas seguidores da linha teórica ECD, os economistas da linha teórica conhecida como Escola de Chicago ${ }^{4}$ defendem que ganhos de eficiência adviriam de estruturas mais concentradas, uma vez que empresas maiores se beneficiariam de economias de escala e escopo. Consequentemente, a Escola de Chicago defende não haver relação entre estrutura, conduta e desempenho: a estrutura de mercado seria consequência da tecnologia, que determinaria o tamanho mais eficiente para uma firma, e da demanda, que determinaria quantas firmas de tamanho ótimo caberiam no mercado, e o desempenho seria sempre ótimo (mesmo com poucas firmas), pois se houvesse qualquer ineficiência, concorrentes seriam atraídos para o mercado. Para chegar a tal resultado, a Escola de Chicago assume ausência de barreiras à entrada, que só seriam criadas, na visão desta linha de pensamento, por meio de políticas públicas reguladoras (concessões públicas). Consequentemente, a Escola de Chicago defende que nenhum tipo de intervenção governamental seja feito.

Qual das duas linhas teóricas melhor representa a realidade? Deve-se reconhecer que, embora na presença de barreiras à entrada as estruturas concentradas de mercado possam estar associadas a abuso de poder de mercado por parte das grandes firmas, como enfatiza o modelo ECD, ganhos de eficiência por parte de firmas maiores, em presença de economias de escala, também podem ocorrer, como ressaltam os adeptos da Escola de Chicago. Portanto, os processos de concentração de mercados costumam ser caracterizados por um trade-off entre os ganhos de eficiência que se teriam em termos de economias de escala ou escopo e a perda de bem-estar decorrente do maior poder de mercado angariado pelas firmas maiores. Logo, é necessário examinar empiricamente cada caso para se chegar a uma conclusão sobre os impactos da concentração de mercado no bem-estar social.

4 Martin (1993) discute detalhadamente os argumentos da Escola de Chicago e os contrapõem ao modelo ECD. 


\section{Metodologia}

\subsection{Evolução de medidas de desempenho}

Em relação ao desempenho, as principais medidas utilizadas na literatura internacional têm sido as taxas de lucro e as razões preço/custo, sendo as últimas derivadas de indicadores como o Índice de Lerner (LERNER, 1934). Uma dificuldade básica que se teria para utilizar tais indicadores, no Brasil, é a carência de dados. Portanto, os principais indicadores utilizados nesta pesquisa são construídos a partir dos preços recebidos pelos varejistas, pelos atacadistas e pelos produtores.

Além do exame do mecanismo de transmissão de preços entre produtor, atacado e varejo, este trabalho também estima margens de comercialização e markups do varejo para que se tenha um panorama mais claro da posição do varejo em relação aos demais participantes do sistema agroalimentar. A margem relativa do varejo consite na parcela do preço pago ao consumidor cabível aos varejistas, enquanto o markup é a margem que os varejistas adicionam ao preço do atacado.

\subsection{Procedimentos econométricos ${ }^{5}$}

\subsubsection{Teste de raiz unitária}

A análise de regressão e a maioria dos métodos de estimação convencionais partem da pressuposição de que as séries são estacionárias, ou seja, de que suas propriedades estocásticas são invariantes com respeito ao tempo (PINDYCK e RUBINFELD, 1991). No presente trabalho utiliza-se o procedimento de Phillips-Perron (PP) para se testar a estacionaridade das séries. Phillips e Perron (1988) propuseram um teste não paramétrico para testar a existência de uma raiz unitária controlando a correlação serial. $\mathrm{O}$ método estima a equação não expandida do teste Dickey-Fuller (DF) e modifica a razão $t$ do coeficiente, de tal forma que a correlação serial não afeta a distribuição assintótica do teste.

\subsubsection{Teste de autocorrelação entre os resíduos}

Outra situação que pode estar presente nas análises econométricas e que afeta particularmente a confiabilidade dos testes de hipóteses é a autocorrelação entre os resíduos. O procedimento utilizado para identificar a presença de autocorrelação neste trabalho é o sugerido por Gujarati (2000), que afirma

\footnotetext{
5 As estimativas e testes de hipóteses deste trabalho utilizam o software Eviews.
} 
ser possível detectar a presença de autocorrelação por meio do modelo autorregressivo de heteroscedasticidade condicional (ARCH). Este modelo pressupõe que a variância do erro aleatório $\mu_{t}$ depende do tamanho do termo de erro passado, elevado ao quadrado.

$\mathrm{O}$ processo $\mathrm{ARCH}(p)$ pode ser escrito da seguinte forma:

$$
\operatorname{Var}\left(\mu_{t}\right)=\alpha_{t}^{2}=\alpha_{0}+\alpha_{t} \mu_{t-1}^{2}+\alpha_{t} \mu_{t-2}^{2}+\ldots+\alpha_{p} \mu_{t-p}^{2}
$$

Se não houver autocorrelação na variância do erro, tem-se $\mathrm{H}_{0}=\alpha_{1}=\alpha_{2}=\ldots=\alpha_{\mathrm{p}}=0$ implicando que a $\operatorname{var}\left(\mu_{\mathrm{t}}\right)=\alpha_{0}$ é homoscedástica. A hipótese $\mathrm{H}_{0}$ pode ser testada por meio do teste $\mathrm{F}$ de uma regressão estimada com $\mu_{\mathrm{t}}$ (erro estimado obtido da equação estimada) ou pelo coeficiente $n \cdot R^{2}$ que segue distribuição qui-quadrado $\left(\chi^{2}\right)$, em que $\mathbf{n}$ é o número de observações e $\mathrm{R}^{2}$ é o coeficiente de determinação obtido a partir da expressão (1).

\subsubsection{Teste de causalidade}

A definição do sentido de causalidade entre os preços é feita por meio de testes de exogeneidade, aplicando-se o procedimento desenvolvido por Granger (1969). Segundo Granger (1969), uma variável $x$ causa uma variável $y$ quando valores correntes e passados de $\mathrm{x}$ ajudam a melhorar a previsão de $y$. Considerando-se a equação:

$$
\mathrm{y}_{\mathrm{t}}=\sum_{\mathrm{j}=1}^{\mathrm{p}} \gamma_{\mathrm{j}} \mathrm{y}_{\mathrm{t}-\mathrm{j}}+\sum_{\mathrm{j}=1}^{\mathrm{p}} \theta_{\mathrm{j}} \mathrm{x}_{\mathrm{t}-\mathrm{j}}+\varepsilon_{\mathrm{t}},
$$

O teste para se verificar se y é causado por x consiste em testar se os coeficientes de $\mathrm{x}$ são nulos; ou seja, se $\theta_{1}=\ldots=\theta_{\mathrm{p}}=0$. Essa verificação pode ser feita pelo tradicional teste $\mathrm{F}$. Analogamente, estima-se uma equação de x em função de y para verificar se esta não está causando aquela.

Na realização dos testes de causalidade, a primeira questão que se apresenta é a definição do número de defasagens a serem incluídas no modelo. Neste estudo, optou-se por testar estatisticamente o número de defasagens a serem incluídas nas equações de transmissão de preços. Cinco critérios de se testar o número de defasagens foram analisados: LR (likelihood ratio $=$ razão de verossimilhança); FPE (final prediction error); AIC (Akaike information criterion); SC (Schwarz information criterion) e HQ (Hannan-Quinn information criterion). A partir desses critérios, a escolha do número de defasagens se baseou na consistência entre os mesmos, ou seja, escolheu-se o número de defasagens que é apontado pela maioria dos testes.

É importante notar que o conceito de causalidade de Granger não implica relação de causa e efeito, sendo baseada apenas em "previsibilidade" (GRIFFITHS et al., 1993). Por esse motivo, o teste de causalidade tem sido 
olhado com bastante reserva por parte dos estudiosos. De qualquer forma, o teste pode trazer indicações importantes sobre as relações de liderança entre os vários níveis de comercialização.

\subsubsection{Teste de assimetria}

O teste de assimetria implementado neste trabalho foi desenvolvido por Wolfram (1971) e aperfeiçoado por Houck (1977). Este teste tem como função identificar se acréscimos ou decréscimos de preços são transmitidos com a mesma intensidade.

Houck (1977) considera um modelo em que a variável dependente, por exemplo, $P v$ é função apenas de uma variável independente, $P a$. Matematicamente, a relação pode ser expressa da seguinte maneira:

$$
\Delta \mathrm{Pv}_{i}=\alpha_{0}+\alpha_{1} \Delta \mathrm{Pa}_{i}^{a c}+\alpha_{2} \Delta \mathrm{Pa}_{i}^{d c}+\varepsilon_{t} \quad \text { para } \quad \mathrm{i}=1,2 \ldots \mathrm{t}
$$

Sendo que:

$$
\begin{array}{lll}
\Delta \mathrm{Pv}_{i}=\mathrm{Pv}_{i}-\mathrm{Pv}_{i-1} & & \\
\Delta \mathrm{Pa}_{i}^{a c}=\mathrm{Pa}_{i}-\mathrm{Pa}_{i-1} & \text { se } \quad \mathrm{Pa}_{i}>\mathrm{Pa}_{i-1} \quad \text { e, } \\
\Delta \mathrm{Pa}_{i}^{a c}=0 & \text { se } \quad \mathrm{Pa}_{i}<\mathrm{Pa}_{i-1} \\
\Delta \mathrm{Pa}_{i}^{d c}=\mathrm{Pa}_{i-1}-\mathrm{Pa}_{i} & \text { se } \quad \mathrm{Pa}_{i}<\mathrm{Pa}_{i-1} \quad \text { e, } \\
\Delta \mathrm{Pa}_{i}^{d c}=0 & \text { se } \quad \mathrm{Pa}_{i}>\mathrm{Pa}_{i-1}
\end{array}
$$

em que $\mathrm{Pv}_{0}$ é o valor inicial de PV; $\mathrm{Pa}_{0}$ é o valor inicial de Pa.

$\mathrm{O}$ valor de $\mathrm{Pv}$ em que um ponto qualquer $t$ será:

$$
\mathrm{Pv}_{t}=\mathrm{Pv}_{o}+\sum_{i=1}^{T} \Delta \mathrm{Pv}_{i} \quad \text { para } \quad \mathrm{i}=1,2,3 \ldots \mathrm{t}, \ldots \mathrm{T}
$$

em que T é o número total de observações, além do valor inicial. A diferença entre os valores corrente e inicial de Pv é a soma, de período a período, das mudanças que têm ocorrido. Assim,

$$
\mathrm{Pv}_{t}-\mathrm{Pv}_{0}=\sum_{\mathrm{i}=1}^{\mathrm{T}} \Delta \mathrm{Pv}_{i}
$$

Substituindo-se a equação (3) na equação (5) e simplificando-a, tem-se

$$
\mathrm{Pv}_{t}-\mathrm{Pv}_{0}=\alpha_{0} \mathrm{t}+\alpha_{1}\left(\sum \Delta \mathrm{Pa}_{i}^{a c}\right)+\alpha_{2}\left(\sum \Delta \mathrm{Pa}_{i}^{d c}\right)
$$

Considerando-se $\mathrm{Y}_{\mathrm{T}}{ }^{*}, \mathrm{Z}_{\mathrm{T}}{ }^{*}$ e $\mathrm{W}_{\mathrm{T}}{ }^{*}$ iguais a (Pvt-Pv0), $\left(\Sigma \Delta \mathrm{Pa}^{\mathrm{ac}}{ }_{\mathrm{i}}\right)$ e $\left(\Sigma \Delta \mathrm{Pa}^{\mathrm{dc}}{ }_{\mathrm{i}}\right)$ respectivamente, e incluindo o termo estocástico $\varepsilon_{t}$ chega-se à equação a ser estimada:

$$
\mathrm{Y}_{\mathrm{t}}^{*}=\alpha_{0 t}+\alpha_{1} \mathrm{Z}_{\mathrm{t}}^{*}+\alpha_{2} \mathrm{~W}_{\mathrm{t}}^{*}+\varepsilon_{t}
$$


Sendo $Z_{t}^{*}$ a soma de todos os acréscimos, período a período, desde o valor inicial até o período $t$, e $W_{t}^{*}$ é o similar para decréscimos. A variável $Z_{t}^{*} e ́$ sempre positiva, ao passo que $W_{t}{ }^{*}$ é sempre negativa. Se $\alpha_{0}$ não for zero, este pode ser considerado como um coeficiente tendência na equação (6). Se alguma outra variável afetasse $\Delta \mathrm{Pv}_{\mathrm{i}}$ na equação (3), esta também poderia ser considerada na equação (7), como os desvios de seus valores iniciais.

O teste de assimetria é feito testando-se a hipótese de que $\alpha_{1}$ é igual a $\alpha_{2}$. Caso se rejeite essa hipótese, há assimetria. Se $\alpha_{1}>\alpha_{2}$, os acréscimos de preços são transmitidos mais intensamente que os decréscimos. Se $\alpha_{1}<\alpha_{2}$, os decréscimos de preços são transmitidos mais intensamente. Vale ressaltar que, no caso de os preços estarem na forma de logaritmos naturais, as elasticidades de transmissão serão os próprios coeficientes da equação estimada $\left(\alpha_{1}\right.$ e $\left.\alpha_{2}\right)$.

\subsubsection{Teste de normalidade de Jarque-Bera}

Trata-se de um teste para verificar se a série tem distribuição normal. $\mathrm{O}$ teste mede a diferença entre a assimetria (skewness) e a curtose da série com as medidas da distribuição normal. A estatística é calculada segundo a seguinte expressão:

$$
\text { Jarque - Bera }=\frac{\mathrm{N}-\mathrm{K}}{6}\left[\mathrm{~S}^{2}+\frac{(\mathrm{K}-3)^{2}}{4}\right]
$$

em que S é a assimetria, Ké a curtose e $\mathrm{N}$ representa o número de coeficientes estimados usados para criar a série.

Sob a hipótese nula de distribuição normal dos erros, a estatística de Jarque-Bera tem distribuição $\mathrm{x}^{2}$ com dois graus de liberdade. A probabilidade reportada no Eviews é a probabilidade de que a estatística de Jarque-Bera seja maior (em valor absoluto) que o valor observado sob a hipótese nula - um pequeno valor de probabilidade leva à rejeição da hipótese nula de distribuição normal.

\subsection{Dados}

Foram utilizados preços médios mensais, ao produtor, atacado/indústria e varejo no estado de São Paulo, sendo sua capital o centro varejista analisado. A fonte de dados de preços é o Instituto de Economia Agrícola (IEA, 2009).

Todos os preços foram convertidos em reais correntes e deflacionados por meio do Índice Geral de Preços - Disponibilidade Interna da Fundação Getúlio Vargas. O período da análise dos preços inicia-se em 1989 para todos os produtos, exceto feijão, cuja base se inicia em abril de 1993. Todas as séries vão até novembro de 2008. 
Os produtos estudados, definidos por sua importância em termos de consumo $^{6}$ e pela disponibilidade de dados para os três níveis de mercado, são: arroz, feijão, carne bovina, carne suína, carne de frango, ovos, queijo minas e óleo de soja.

\section{Resultados e discussão}

\subsection{Impacto da concentração nos markups}

Estudos citados no início deste artigo (FARINA e NUNES, 2002; AGUIAR, 2009), utilizando dados agregados, sugerem que o desempenho econômico melhorou à medida que as firmas varejistas maiores aumentaram suas participações no mercado. Seria este resultado passível de generalização ou as firmas estariam explorando poder no mercado de alguns tipos de produtos? Para analisar esta questão, a presente pesquisa examina as relações entre concentração e desempenho para os oito produtos citados no item anterior. Para todos esses produtos foram calculados os markups do varejo e foi estimada a correlação entre este markup (medida de desempenho) e o grau de concentração do mercado varejista (medida de estrutura). No caso deste indicador de desempenho, maior valor do markup implica pior desempenho econômico (pior nível de bem-estar) e vice-versa. Portanto, correlação positiva entre as duas variáveis indicaria que mercados mais concentrados estariam associados a um maior uso de poder de mercado, enquanto que correlação negativa daria suporte à hipótese de ganhos de eficiência em mercados mais concentrados. Devido à indisponibilidade de algumas séries para períodos mais amplos, a análise baseou-se no período 1994- 2006.

Os resultados apresentados no Quadro 1 sugerem, coerentemente com a hipótese deste trabalho, que a relação entre concentração do mercado e desempenho econômico varia de acordo com o produto considerado. Grosso modo, há uma relação direta entre a concentração de mercado e o markup do varejo para arroz, carne bovina, ovos e feijão, havendo uma correlação negativa nos casos de queijo, carne suína e óleo de soja. No caso da carne de frango, a correlação é muito próxima de zero.

6 Ver dados da Pesquisa de Orçamento Familiares de 1996 (IBGE, 2002). 
Quadro 1. Correlações entre desempenho (Markup) e três indicadores de concentração (H, CR3 e CR5) do mercado varejista, 1994-2006*.

\begin{tabular}{|c|c|c|c|}
\hline Produto & \multicolumn{3}{|c|}{ Índice de Concentração Considerado } \\
\hline & $H$ & CR3 & CR5 \\
\hline Arroz & 0,96289 & 0,94846 & 0,93885 \\
\hline Feijão & 0,13652 & 0,18862 & 0,34259 \\
\hline Carne bovina & 0,56073 & 0,63145 & 0,56932 \\
\hline Carne de frango & 0,05923 & 0,16866 & 0,00796 \\
\hline Carne suína & $-0,46672$ & $-0,43180$ & $-0,48025$ \\
\hline Óleo de soja & $-0,14234$ & $-0,13393$ & $-0,23287$ \\
\hline Queijo & $-0,74176$ & $-0,69505$ & $-0,63707$ \\
\hline Ovo & 0,39621 & 0,46379 & 0,38270 \\
\hline
\end{tabular}

${ }^{*}$ Markup = markup médio anual dos varejistas; CR3 e CR5 são, respectivamente, as taxas de concentração das três e das cinco maiores redes de supermercados; H é o índice de Herfindhal-Hirschman.

Fonte: Resultados da pesquisa.

Portanto, quando são utilizados indicadores de desempenho mais desagregados (em nível de produto), nota-se que para metade dos oito produtos analisados, o markup dos varejistas aumentou com a elevação da concentração do mercado. Para três produtos, o resultado foi inverso. E, apenas no caso da carne de frango, não se identificou correlação entre estrutura e desempenho.

É interessante notar que os produtos para os quais as correlações foram negativas (particularmente queijo tipo minas e óleo de soja) são produtos populares e, por isso mesmo, são produtos muitas vezes utilizados pelos supermercados para atrair consumidores. No caso da carne suína, a correlação negativa entre markup e concentração de mercado poderia decorrer da elevada elasticidade-preço da demanda deste produto $^{7}$, o que poderia justificar a estratégia de redução de preços e aumento de vendas para elevar a receita bruta dos varejistas. Por outro lado, produtos com demanda mais inelástica a preço (arroz e feijáo) ou de maior elasticidade-renda (carne bovina) permitiriam maior exercício de poder de mercado.

\subsection{Participação dos varejistas no dispêndio dos consumidores}

Prosseguindo a busca de evidências de uso de poder de mercado por parte dos varejistas, um indicador de grande relevância pode ser a margem relativa de comercialização dos varejistas. Aguiar e Silva (2002) haviam identificado

7 Brandt (1980), por exemplo, apresenta estimativa de elasticidade-preço da demanda de 2,21 para carne suína. 
um aumento desta margem no setor de comercialização de carne bovina entre 1994 e 1999, atribuindo a tal fato o aumento de poder de mercado devido à concentração do mercado varejista. Em função disso, pelo menos duas questões se fazem presentes: (I) a hipótese levantada por Aguiar e Silva (2002) continua sendo válida no período mais recente? e (II) esta hipótese poderia ser generalizada para outros produtos?

Para examinar tais questões, a Figura 1 apresenta as margens relativas de comercialização dos varejistas de cada um dos produtos analisados neste trabalho. Nota-se que os resultados variam de produto para produto. Embora não haja evidência de tendências, verifica-se uma mudança no patamar das margens relativas de alguns produtos, tais como arroz, carne bovina, carne de frango, carne suína e ovos, com maior participação dos varejistas no dispêndio do consumidor a partir de 1997, quando se deu um maior nível de concentração no setor. Para os demais produtos, não há evidências de alteração.

Analisando-se produto a produto, nota-se:

- Arroz - As margens não são tão elevadas, provavelmente por ser um produto estocável pouco sujeito a perdas de comercialização. Mesmo assim, nota-se aumento expressivo da margem relativa de comercialização do varejo após 1999, atingindo aproximadamente $15 \%$.

- Feijão - As margens são maiores do que para o arroz, o que se deve ao maior índice de perdas de comercialização do feijão em relação ao arroz. Não há evidências de alterações ao longo do período. Na maioria dos anos, a margem relativa de comercialização do varejo de feijão é em torno de $40 \%$.

- Carne bovina - Muda o patamar entre 1993 e 1997, conforme Aguiar \& Silva (2002) já haviam constatado. Desde então, a margem relativa do varejista tem se mantido estável em torno de $50 \%$.

- Carne de frango - Embora a margem varie bastante, há uma mudança de patamar ao longo do tempo, pois a margem se situava em torno de $20 \%$ até 1994 e tem ficado acima de $30 \%$ nos últimos anos.

- Carne suína - A margem relativa do varejo de carne suína tem oscilado entre 50\% e 60\%. Antes de 1994, situava-se um pouco abaixo de 50\%. Há, portanto, uma pequena diferença de patamar ao longo dos anos.

- Ovos - O mercado de ovos apresenta grande mudança de patamar da margem relativa de comercialização do varejo. A margem se situava abaixo de 30\% e passou a cerca de 50\% desde 1996.

- Queijo-Não há mudança a parente na margem relativa de comercialização do varejo do queijo minas, embora tenha havido uma queda nos últimos dois anos (que pode ser transitória).

- Óleo de soja - Há grandes oscilações, mas sem mudança aparente de patamar. 
Figura 1. Margens relativas de comercialização dos varejistas de arroz, feijão, carne bovina, carne de frango, carne suína, ovos, queijo minas e óleo de soja no estado de São Paulo, 1989-2008.
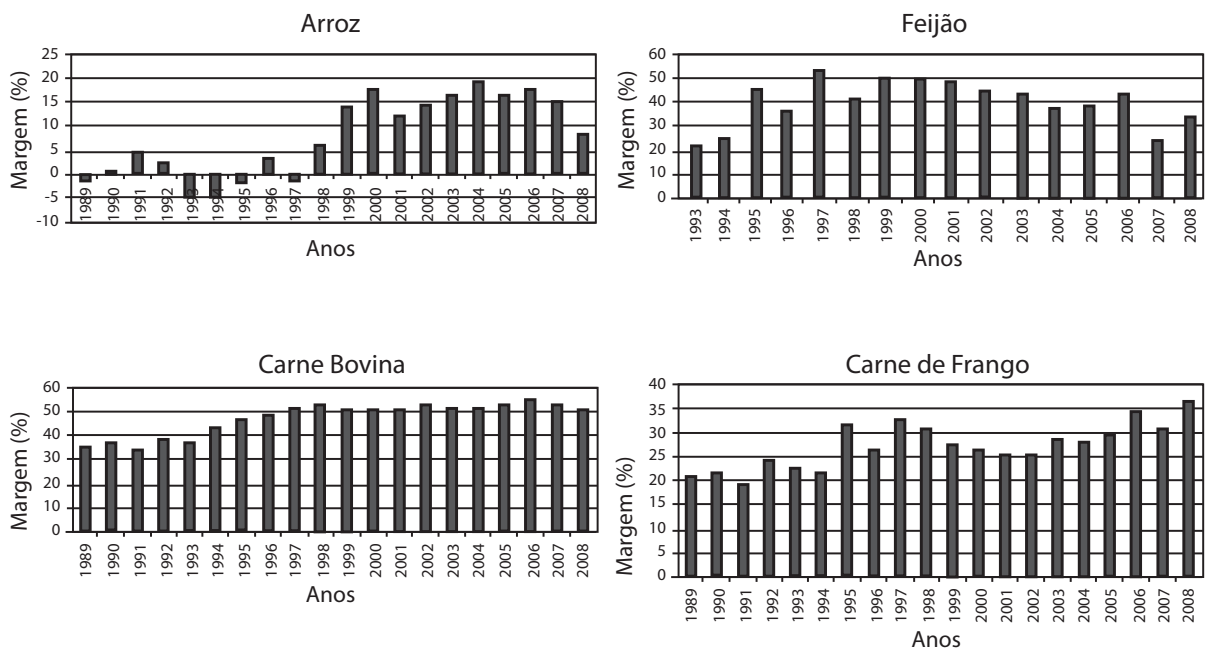

Carne Suína

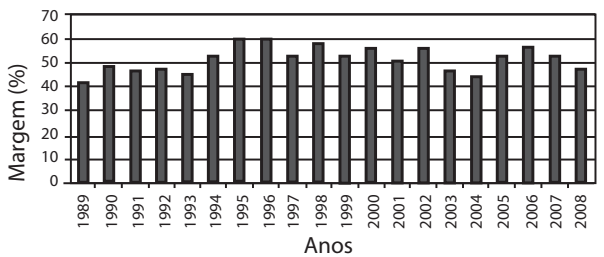

Ovos

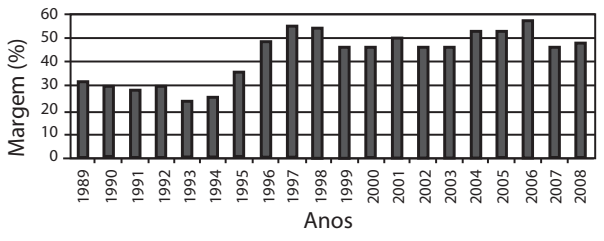

Queijo Minas

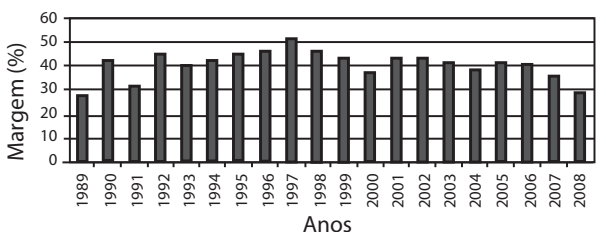

Óleo de Soja

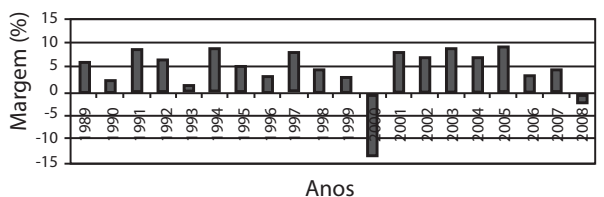

Fonte: Resultados da pesquisa.

\subsection{Análise econométrica da transmissão de preços}

A análise do mecanismo de transmissão de preços segue os passos indicados no item 3.1. Iniciando com os testes de raiz unitária, seus resultados mostram que 
todas as séries são estacionárias em nível, com exceção das séries de logaritmos dos preços e das séries de acréscimos e decréscimos de preços de três produtos: óleo de soja, ovos e queijo. Porém, estas séries se mostraram estacionárias em primeiras diferenças. Para estas séries I(1) foram feitos testes de cointegração, que mostraram, com base no teste do traço, ao nível de significância de 5\%, a existência de três vetores de cointegração. Como todas as séries são estacionárias ou cointegradas com posto completo (todas com três vetores de integração), seguiu-se a sugestão de Seddighi et al. (2000) e Lütkepohl e Krätzig (2004) para lidar com tais situações, de forma que as equações de transmissão de preços puderam ser estimadas em nível ${ }^{8}$.

\subsubsection{Testes de causalidade de Granger}

$\mathrm{Na}$ realização dos testes de causalidade, a definição das defasagens significativas se deu pelo procedimento descrito no item 3.1.3. Dos cinco critérios usados para se testar o número de defasagens, dois deles apresentaram sempre os mesmos números de defasagens significativas: FPE (final prediction error) e AIC (Akaike information criterion). Por isso, optou-se por utilizar as defasagens apontadas por estes dois últimos critérios. As defasagens utilizadas foram: arroz $=5$; feijão $=2$; carne bovina $=10$; carne de frango $=9$; ovos $=3$; queijo $=8$; óleo de soja $=2$; carne suína $=10$.

Os resultados dos testes de causalidade podem ser observados na Figura 2. Nota-se forte participação do atacado na formação de preços, sendo que apenas nos mercados de feijão, carne suína e carne de frango não haveria causalidade do preço no atacado para o preço ao produtor. A importância do preço ao produtor nos mercados de frango e suínos pode ser resultado das relações contratuais que ocorrem nestas cadeias produtivas, enquanto que no caso do feijão, os frequentes choques de oferta a que este produto está sujeito poderiam justificar a importância do preço ao produtor. Mesmo assim, algumas incoerências ilustram a necessidade de se ter cuidado na aceitação dos resultados dos testes de causalidade.

8 Situação semelhante foi encontrada por Lass (2005), que utilizou o mesmo procedimento adotado no presente trabalho. 
Figura 2. Sentidos de causalidade na transmissão de preços agrícolas.
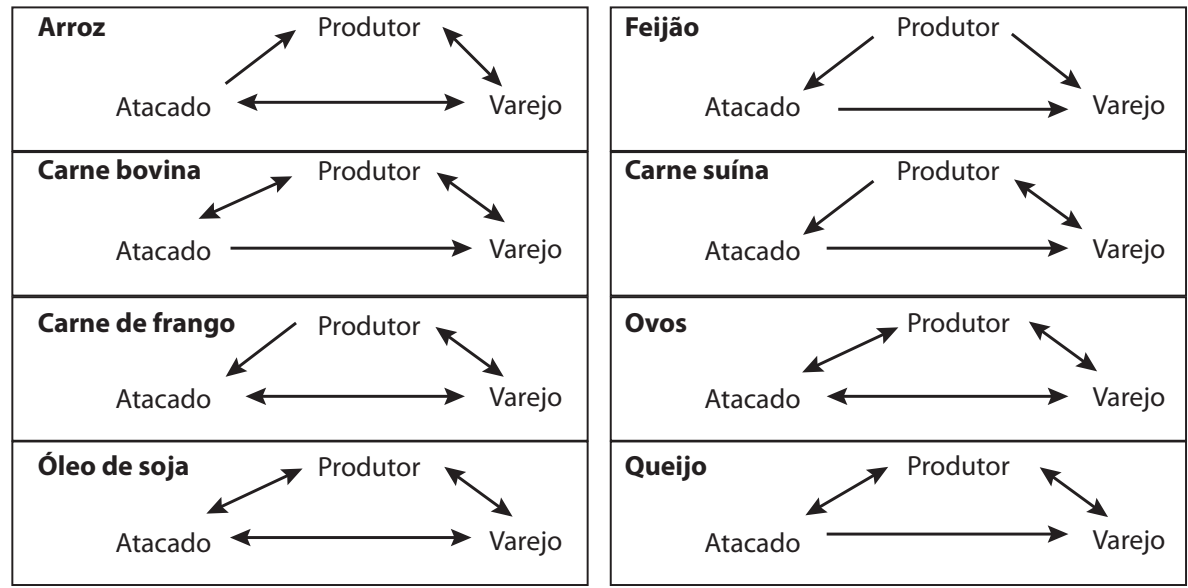

Fonte: Resultados da pesquisa.

Dada a inconclusividade típica de testes de assimetria e a importância do atacado na formação de preços, constatada tanto neste como em outros inúmeros trabalhos, a análise da assimetria na transmissão de preços verificará os efeitos de acréscimos e decréscimos no preço ao atacado sobre os preços ao varejo e ao produtor.

O fato de o atacado normalmente iniciar as variações de preços decorre de suas características estruturais. Geralmente, poucos agentes operam neste nível de mercado e o grau de especialização é o maior entre todos os níveis de mercado, sendo bastante comum encontrarem-se atacadistas operando com apenas um tipo de produto. Em função disso, os atacadistas detêm mais informações do que os empresários que atuam nos demais níveis de mercado. Segundo Eckstein e Fromm (1968), o fato de a formação do preço ocorrer em nível de atacado se deve, além do maior acesso às informações, às seguintes condições encontradas neste nível de mercado: (I) o custo de mudança de preço é desprezível, por serem as vendas centralizadas em local e tempo definidos e (II) as transações são bastante frequentes, de forma que vendedores e compradores se manteriam em comunicação e poderiam se entender mais ou menos continuamente acerca de alterações de preços.

\subsubsection{Análise da assimetria na transmissão de preços}

\section{Assimetria na transmissão de preços no período completo}

As equações para os testes de assimetria foram estimadas com os preços em logaritmos neperianos, de forma que os resultados já representam 
elasticidades de transmissão de preços. Todas as equações foram estimadas pelo método de máxima verossimilhança, o que fez com que os resíduos assumissem distribuição normal, conforme foi verificado por meio do teste de Jarque-Bera.

Tanto neste quanto no próximo item, os efeitos referidos como de curto prazo são os efeitos ocorridos no mês corrente (sem defasagem), enquanto que os efeitos de longo prazo correspondem às somas dos efeitos de todos os meses considerados até o número máximo de defasagens significativas de cada equação de transmissão de preços.

Neste item são apresentados os resultados das estimações das equações de transmissão de preços e testes de assimetria na transmissão de preços para as séries completas, de janeiro de 1989 a dezembro de 2008 (no caso do feijão, a série começa em janeiro de 1993). No item subsequente haverá a segmentação deste período em dois subperíodos.

a) Transmissão entre atacado e varejo

O Quadro 2 apresenta um resumo dos resultados referentes à análise da assimetria na transmissão de preços no curto e no longo prazo. Nota-se a presença de assimetria na transmissão de preços de todos os produtos, seja só no curto prazo, apenas no longo prazo, ou em ambos os casos. Nota-se ainda que, em todos os testes que tiveram a hipótese de simetria rejeitada, os acréscimos dos preços no atacado foram transmitidos pelos varejistas mais intensamente do que os decréscimos.

Este resultado é consistente com o encontrado por Aguiar e Santana (2002) e é um indício de uso de poder de mercado por parte do setor varejista. Entretanto, para três produtos (arroz, ovos e carne de frango), a assimetria verificada no curto prazo é compensada no mês seguinte, ou seja, há assimetria no curto prazo e simetria no longo prazo, o que sugere que, para estes produtos, a diferença está na rapidez da resposta do setor varejista a acréscimos de preços. Havendo aumento de preços ao atacado, os varejistas rapidamente transmitem tal aumento aos consumidores, mas no caso de queda no preço ao atacado, esta queda é transmitida mais lentamente pelos varejistas. Já no caso do queijo e da carne suína, ocorre o contrário, havendo simetria no curto prazo e assimetria no longo prazo, indicando que os varejistas transmitiriam mais intensamente os acréscimos de preços destes produtos, mas o fariam ao longo do tempo. 
Quadro 2. Elasticidades de acréscimo e de decréscimo de preços entre atacado e varejo, de curto e longo prazos, e testes de simetria dos produtos analisados no período completo.

\begin{tabular}{|c|c|c|c|c|c|c|}
\hline \multirow{2}{*}{ Produto } & \multicolumn{3}{|c|}{ Efeito de Curto Prazo } & \multicolumn{3}{c|}{ Efeito de Longo Prazo } \\
\cline { 2 - 7 } & Acréscimo & Decréscimo & Teste & Acréscimo & Decréscimo & Teste \\
\hline Arroz & $0,6610^{*}$ & $0,3364^{*}$ & $24,99^{*}$ & $0,7883^{*}$ & $0,8044^{*}$ & 0,08 \\
\hline Feijão & $0,3728^{*}$ & $0,0896^{* *}$ & $17,48^{*}$ & $0,6813^{*}$ & $0,3171^{(\mathrm{a})}$ & $19,91^{*}$ \\
\hline Carne Bovina & $0,5574^{*}$ & $0,4422^{*}$ & $29,10^{*}$ & $0,6561^{*}$ & $0,5732^{*}$ & $13,97^{*}$ \\
\hline Carne de frango & $0,5075^{*}$ & $0,3528^{*}$ & $3,23^{* * *}$ & $0,6175^{(\mathrm{b})}$ & $0,6031^{*}$ & 0,05 \\
\hline Ovos & $0,5527^{*}$ & $0,2093^{*}$ & $23,92^{*}$ & $0,4464^{*}$ & $0,4452^{*}$ & 0,00 \\
\hline Óleo de Soja & $0,4224^{*}$ & $0,2359^{*}$ & $19,21^{*}$ & $0,6176^{*}$ & $0,4881^{*}$ & $6,14^{* *}$ \\
\hline Queijo & $0,2840^{*}$ & $0,2673^{*}$ & 0,05 & $0,5419^{*}$ & $0,4221^{*}$ & $71,78^{*}$ \\
\hline Carne suína & $0,3444^{*}$ & $0,2357^{*}$ & 2,22 & $0,4887^{*}$ & $0,4032^{*}$ & $2,71^{* * *}$ \\
\hline
\end{tabular}

* Significativo a $1 \%$.

** Significativo a $5 \%$.

*** Significativo a $10 \%$.

(a) a elasticidade corrente foi significativa a $5 \%$ e a defasada a $1 \%$.

(b) a elasticidade corrente foi significativa a $1 \%$ e a defasada a $10 \%$

Fonte: Resultados da pesquisa.

Outro aspecto que merece atenção é que todas as elasticidades de transmissão de preços são menores que a unidade, ou seja, o varejo atenua as variações dos preços ocorridas em nível de atacado. Tal resultado, compatível com os resultados de inúmeros outros trabalhos sobre a transmissão de preços agrícolas ${ }^{9}$, não representa, como poderia parecer em um primeiro momento, indício de que os varejistas não estariam usando seu poder de mercado. $\mathrm{O}$ que justifica a existência de elasticidades de transmissão de preços menores do que a unidade é o fato de o produto final comercializado no varejo ser uma combinação do produto adquirido no atacado com um conjunto de insumos de comercialização (serviços de transporte, armazenamento, eletricidade, mão de obra etc.), cujos preços variam menos do que o preço da mercadoria agrícola ${ }^{10}$. Com isso, ter-se-iam, naturalmente, elasticidades de transmissão de preços menores do que a unidade.

\section{b) Transmissão entre atacado e produtor}

Um resumo dos resultados referentes à análise da simetria na transmissão de preços entre atacado e produtor é apresentado no Quadro 3. Notam-se diversas diferenças em relação à transmissão feita pelos varejistas analisada no item anterior.

\footnotetext{
9 Ver Aguiar (1993) para uma síntese da literatura sobre o assunto.

10 Ver Barros (1987).
} 
No caso da transmissão para o preço do produtor, há vários casos de transmissão mais intensa dos decréscimos do que dos acréscimos do preço no atacado, fato que não ocorria com os varejistas. Esta situação está presente nos mercados de arroz, carne bovina, queijo e carne suína, seja no curto prazo, no longo prazo, ou em ambos. Apenas nos mercados de ovos e óleo de soja houve transmissão mais intensa dos acréscimos de preços, sendo que no mercado de carne de frango houve transmissão simétrica de preços.

Outro aspecto notável é que o valor das elasticidades é normalmente maior na transmissão atacado-produtor do que na transmissão atacado-varejo, sendo que em dois casos não se rejeita a hipótese de que a elasticidade seja maior do que a unidade: no mercado de arroz, não se rejeita que a elasticidade de decréscimo de preços de longo prazo seja maior que a unidade ao nível de significância de $5 \%$ (teste Wald $=4,15$ ); e no mercado de feijão, não se rejeita que a elasticidade de acréscimo de preços de longo prazo seja maior que a unidade também ao nível de significância de $5 \%$ (teste Wald $=5,26$ ). A justificativa para esta constatação é análoga à dada no item anterior: o preço do produto agrícola ao produtor tenderia a variar mais porque o preço ao atacado já inclui insumos de mercado.

Quadro 3. Elasticidades de acréscimo e de decréscimo de preços entre atacado e produtor, de curto e de longo prazos, e os testes de simetria dos produtos analisados no período completo.

\begin{tabular}{|c|c|c|c|c|c|c|}
\hline \multirow{2}{*}{ Produto } & \multicolumn{3}{|c|}{ Efeito de Curto Prazo } & \multicolumn{3}{c|}{ Efeito de Longo Prazo } \\
\cline { 2 - 7 } & Acréscimo & Decréscimo & Teste & Acréscimo & Decréscimo & Teste \\
\hline Arroz & $0,5209^{*}$ & $0,7789^{*}$ & $114,41^{*}$ & $0,9069^{*}$ & $1,0363^{*}$ & $59,04^{*}$ \\
\hline Feijão & $0,7692^{*}$ & $0,6188^{*}$ & $64,36^{*}$ & $1,0371^{*}$ & $0,9796^{*}$ & 121,45 \\
\hline Carne Bovina & $0,6023^{*}$ & $1,1030^{*}$ & $14,48^{*}$ & $0,8429^{*}$ & $0,8560^{*}$ & 1,53 \\
\hline Carne de frango & $0,6921^{*}$ & $0,8209^{*}$ & 1,09 & $0,6921^{*}$ & $0,8209^{*}$ & 1,09 \\
\hline Ovos & $0,8245^{*}$ & $0,6137^{*}$ & $8,99^{*}$ & $0,8245^{*}$ & $0,7161^{(\mathrm{a})}$ & $4,69^{* *}$ \\
\hline Óleo de Soja & $0,5004^{*}$ & $0,4365^{*}$ & 0,21 & $0,5004^{*}$ & $0,2737^{(\mathrm{a})}$ & $3,44^{* * *}$ \\
\hline Queijo & 0,0194 & $0,1117^{* * *}$ & 1,00 & $0,1235^{* *}$ & $0,2329^{(\mathrm{b})}$ & $3,99^{* *}$ \\
\hline Carne suína & $0,4470^{*}$ & $0,8258^{*}$ & $29,29^{*}$ & $0,7625^{*}$ & $0,8823^{(\mathrm{a})}$ & $385,74^{*}$ \\
\hline
\end{tabular}

* Significativo a $1 \%$

** Significativo a $5 \%$.

*** Significativo a $10 \%$

(a) a elasticidade defasada de um mês foi significativa a $10 \%$.

(b) a elasticidade corrente foi significativa a $10 \%$ e a defasada de um mês a $5 \%$.

Fonte: Resultados da pesquisa.

A constatação de que predomina transmissão mais intensa dos acréscimos de preços por parte dos varejistas, e transmissão mais intensa de decréscimos entre atacado e produtor, reforça a hipótese de uso de poder de mercado por parte dos varejistas. Tipicamente, o setor de produção agrícola não apresenta 
poder de mercado por se aproximar estruturalmente do mercado perfeitamente competitivo. Já o mercado varejista, por sua estrutura concentrada, teria condições de interferir na formação do preço, enquanto que os atacadistas, por suas características estruturais, teriam maior poder de mercado em suas relações com os agricultores do que com os varejistas.

\section{Assimetria na transmissão de preços: diferenças entre 1989-1999 e 2000-2008}

Na sequência da análise, as séries são segmentadas em dois períodos: o período 1, que vai de 1989 a 1999 e o período 2, que vai de 2000 a 2008, para se verificar se houve mudança no mecanismo de transmissão de preços entre esses dois períodos, uma vez que, até 1999, ocorreu grande parte do processo de concentração de mercado. Nesta parte da análise, apenas as relações entre atacado e varejo são analisadas, visto que a segmentação da análise em dois períodos se justificou pelas mudanças ocorridas na estrutura do mercado varejista.

Observando-se inicialmente o Quadro 4, que trata das análises de curto prazo, nota-se que a transmissão mais intensa dos acréscimos de preços predomina no primeiro período. O Teste 1 mostra que apenas os mercados de carne bovina e queijo apresentaram transmissão simétrica de preços no período 1 , sendo que todos os demais produtos tiveram transmissão mais intensa de acréscimos de preços neste período. No período 2, apenas o mercado de óleo de soja apresentou transmissão mais intensa de acréscimos de preços (ao nível de significância de 10\%), não se rejeitando a hipótese de simetria para os demais produtos (Teste 2).

O Teste 3, na penúltima linha do Quadro 4, mostra ainda que as elasticidades de transmissão de acréscimos de preços no período 1 foram maiores do que as elasticidades de transmissão de acréscimos de preços no período 2 para seis dos oito produtos, não sendo significativo o teste para óleo de soja e queijo. Ou seja, os varejistas transmitiam mais intensamente os acréscimos de preços antes do ano 2000 do que no período posterior. Em relação à transmissão de decréscimos de preços, o Teste 4 mostra que não houve diferenças entre os dois períodos para cinco produtos, sendo que os valores das elasticidades de transmissão de decréscimos de preços foram maiores no segundo período para carne bovina e óleo de soja. Apenas no mercado de carne suína teria ocorrido uma redução na elasticidade de transmissão de decréscimos de preços no segundo período em relação ao primeiro, mas o valor negativo encontrado é oposto ao esperado. 
Quadro 4. Elasticidades de acréscimo e de decréscimo de preços de curto prazo estimadas nos períodos 1 (1989-1999) e 2 (2000-2008) e testes de hipótese diversos dos produtos analisados.

\begin{tabular}{|c|c|c|c|c|c|c|c|c|}
\hline \multirow{2}{*}{$\begin{array}{c}\text { Estima- } \\
\text { tivas }\end{array}$} & \multicolumn{7}{|c|}{ Mercados } \\
\cline { 2 - 9 } & Arroz & Feijão & $\begin{array}{c}\text { Carne } \\
\text { Bovina }\end{array}$ & Frango & Ovos & $\begin{array}{c}\text { Óleo de } \\
\text { Soja }\end{array}$ & Queijo & $\begin{array}{c}\text { Carne } \\
\text { Suína }\end{array}$ \\
\hline Eac-P1 & 1,0148 & 0,3788 & 0,7378 & 0,8058 & 0,6176 & 0,6417 & 0,3139 & 0,5395 \\
\hline Edc-P1 & 0,3707 & 0,1622 & 0,5510 & 0,4150 & 0,2918 & 0,3251 & 0,2994 & 0,3116 \\
\hline Eac-P2 & 0,2386 & 0,2106 & 0,1296 & 0,2624 & 0,1663 & 0,6417 & 0,3139 & 0,0622 \\
\hline Edc-P2 & 0,3007 & 0,0338 & 0,1584 & 0,4150 & 0,1361 & 0,7120 & 0,2994 & $-0,1535$ \\
\hline Teste 1 & $40,82^{*}$ & $7,54^{*}$ & 1,65 & $11,67^{*}$ & $6,42^{* *}$ & $5,51^{* *}$ & 0,01 & $3,81^{* *}$ \\
\hline Teste 2 & 0,13 & $2,66^{(a)}$ & 0,02 & 0,34 & 0,03 & $2,85^{* * *}$ & 0,01 & 0,63 \\
\hline Teste 3 & $45,61^{*}$ & $4,51^{* *}$ & $17,24^{*}$ & $24,51^{*}$ & $20,06^{*}$ & 2,59 & NS & $5,76^{* *}$ \\
\hline Teste 4 & 0,23 & 2,07 & $5,65^{*}$ & 0,66 & 1,01 & $8,09^{*}$ & NS & $12,14^{*}$ \\
\hline
\end{tabular}

Variáveis:

Eac-P1 = elasticidade de transmissão de acréscimos de preços no período 1 (1989-1999).

Edc-P1 = elasticidade de transmissão de decréscimos de preços no período 1 (1989-1999).

Eac-P2 = elasticidade de transmissão de acréscimos de preços no período 2 (2000-2008).

Edc-P2 = elasticidade de transmissão de decréscimos de preços no período 2 (2000-2008).

Teste 1 simetria no período 1 .

Teste 2 simetria no período 2 .

Teste 3 Eac-P1 = Eac-P2.

Teste 4 Edc-P1 = Edc-P2.

* significativo a $1 \%$; ${ }^{* *}$ significativo a $5 \%$; ${ }^{* *}$ significativo a $10 \%$.

(a) nível de significância de $10,26 \%$.

Fonte: Resultados da pesquisa.

Portanto, os resultados sugerem que os varejistas tiveram maior poder de mercado no primeiro período. A eliminação, no segundo período, da assimetria na transmissão instantânea de preços, que havia sido identificada no período 1 para a maioria dos produtos, ocorreu em razão da redução na elasticidade de transmissão de acréscimos de preços e não em decorrência de alterações na elasticidade de transmissão de decréscimos de preços. Ou seja, a alteração verificada entre os dois períodos sugere que os varejistas passaram a ter maior dificuldade para transmitir instantaneamente os acréscimos de preços no período 2, situação que não ocorria no período 1 . Uma possível explicação para esta mudança reside no aumento da rivalidade entre as empresas varejistas no período 2, conforme se pôde identificar por meio da análise de turnover.

No caso das elasticidades de transmissão de preços no longo prazo (Quadro 5), não se identificam alterações entre os períodos, uma vez que cinco produtos tiveram transmissão assimétrica tanto no período 1 quanto no período 2 , enquanto que os outros três produtos tiveram simetria em ambos os períodos. Entre os cinco produtos que apresentaram transmissões assimétricas, quatro mantiveram o mesmo comportamento nos dois períodos (maior transmissão de acréscimos de preços), enquanto que um (ovos) teve uma inversão no 
mecanismo de transmissão de preços, pois transmitia mais intensamente os decréscimos de preços no período 1 e passou a transmitir mais os acréscimos a partir do ano 2000.

Também na comparação entre as elasticidades, não se identifica um padrão tão definido na transmissão de longo prazo como havia sido constatado na transmissão de curto prazo. Conforme o Teste 3 , dos quatro produtos que tiveram diferenças na elasticidade de transmissão de acréscimos de preços, dois tiveram aumento (arroz e óleo de soja) e dois tiveram diminuição da elasticidade (feijão e carne suína). Dos três produtos que apresentaram diferenças na transmissão de decréscimos de preços, um teve aumento na elasticidade de transmissão de decréscimos de preços (óleo de soja) e dois tiveram redução nesta elasticidade (arroz e carne suína).

Dessa forma, as evidências sugerem que os impactos mais expressivos que indicam uso de poder de mercado, considerando-se a transmissão mais intensa dos acréscimos de preços como um indicador do exercício do poder de mercado, ocorrem instantaneamente, diluindo-se à medida que os mercados se ajustam e a rivalidade dificulta a exploração de poder de mercado. Mas este efeito, mesmo que de curto prazo, era mais evidente no período 1.

Quadro 5. Elasticidades de acréscimo e de decréscimo de preços nos períodos 1 (19891999) e 2 (2000-2008), de longo prazo, e testes de hipótese diversos dos produtos analisados.

\begin{tabular}{|c|c|c|c|c|c|c|c|c|}
\hline \multirow{2}{*}{$\begin{array}{c}\text { Estima- } \\
\text { tivas }\end{array}$} & \multicolumn{7}{|c|}{ Mercados } \\
\cline { 2 - 9 } & Arroz & Feijão & $\begin{array}{c}\text { Carne } \\
\text { Bovina }\end{array}$ & Frango & Ovos & $\begin{array}{c}\text { Óleo de } \\
\text { Soja }\end{array}$ & Queijo & $\begin{array}{c}\text { Carne } \\
\text { Suína }\end{array}$ \\
\hline Eac-P1 & 1,0148 & 0,6229 & 0,7378 & 0,6615 & 0,4304 & 0,8101 & 0,6272 & 0,5395 \\
\hline Edc-P1 & 1,0989 & 0,4189 & 0,5510 & 0,7160 & 0,4906 & 0,7196 & 0,5342 & 0,5610 \\
\hline Eac-P2 & 0,7396 & 0,4547 & 0,6836 & 0,6148 & 0,3838 & 1,1481 & 0,6272 & 0,0622 \\
\hline Edc-P2 & 1,0989 & 0,2904 & 0,5049 & 0,7160 & 0,3349 & 0,8226 & 0,5342 & 0,3749 \\
\hline Teste 1 & 1,18 & $7,92^{*}$ & $5,29^{* *}$ & 1,33 & $7,66^{*}$ & $31,52^{*}$ & $63,68^{*}$ & 0,11 \\
\hline Teste 2 & 2,14 & $5,43^{* *}$ & $4,91^{* *}$ & 1,98 & $14,31^{*}$ & $36,31^{*}$ & $63,68^{*}$ & 0,11 \\
\hline Teste 3 & $13,65^{*}$ & $2,96^{* * *}$ & 0,39 & 0,23 & $2,64(\mathrm{a})$ & $6,18^{* *}$ & $\mathrm{NS}$ & $5,76^{* *}$ \\
\hline Teste 4 & $16,02^{*}$ & 2,25 & 0,35 & 0,17 & 1,10 & $5,24^{* *}$ & $\mathrm{NS}$ & $12,49^{*}$ \\
\hline
\end{tabular}

Variáveis:

Eac-P1 = elasticidade de transmissão de acréscimos de preços no período 1 (1989-1999).

Edc-P1 = elasticidade de transmissão de decréscimos de preços no período 1 (1989-1999)

Eac-P2 = elasticidade de transmissão de acréscimos de preços no período 2 (2000-2008).

Edc-P2 = elasticidade de transmissão de decréscimos de preços no período 2 (2000-2008).

Teste 1 simetria no período 1 .

Teste 2 simetria no período 2.

Teste 3 Eac-P1 = Eac-P2.

Teste 4 Edc-P1 = Edc-P2.

* significativo a $1 \% ;{ }^{* *}$ significativo a $5 \% ;{ }^{* * *}$ significativo a $10 \%$.

(a) $10,4 \%$.

NS dummies não significativas.

Fonte: Resultados da pesquisa. 


\section{Conclusões}

Diante do processo de mudança estrutural pelo qual vem passando o mercado varejista brasileiro, em que o processo de concentração se fez acompanhar de um aumento da rivalidade entre as empresas maiores, a análise econométrica do mercanismo de transmissão de preços realizado no presente estudo trouxe uma série de indicações da forma como o poder de mercado pode estar sendo exercido no setor.

As principais conclusões e implicações deste trabalho são:

- Deve-se evitar a realização de estudos muito agregados sobre o uso de poder de mercado de um setor multiproduto como o varejista, visto que estes estudos podem esconder o uso de poder em mercados específicos.

- No caso de produtos alimentares, o varejo aparentemente desfruta de maior poder nos mercados dos produtos de maior preferência por parte dos consumidores. Dessa forma, os mercados de produtos com demandas mais inelásticas a preço (arroz e feijão) ou com maior elasticidade-renda (carne bovina), aparentemente se mostram mais sujeitos ao exercício de poder de mercado do que outros produtos. São sobre estes produtos que os órgãos de defesa de concorrência deveriam se preocupar mais em suas análises.

- A rivalidade entre as empresas pode estar dificultando o exercício de poder de mercado por parte das mesmas. Por isso, o exercício de poder de mercado dos varejistas sobre os consumidores aparentemente se reduziu na presente década. Mas o exercício de poder de mercado via preço pode voltar a aumentar caso haja a redução da rivalidade que caracteriza o setor atualmente.

- O exercício de poder de mercado via preço tem também um componente temporal. Em geral, as transmissões mais intensas dos acréscimos de preços se dão instantaneamente, enquanto que as transmissões de decréscimos de preços tendem a ser mais demoradas.

- Apesar das limitações que existem em termos de bases de dados para a maioria dos estados da federação, seria desejável que estudos similares a este fossem feitos para outros estados para se identificar o poder de generalização dos resultados aqui encontrados. Seria desejável também que outros estudos examinassem uma gama maior de produtos, o que não foi feito neste estudo pela limitação da base de dados usada. Havendo disponibilidade, mais desejável ainda seria a utilização de dados em nível de empresa.

- Apesar de todas as limitações com as séries de dados, a análise da assimetria na transmissão de preços mostrou-se um instrumento poderoso para identificar o uso de poder de mercado via preço. 
- Como boa parte do uso de poder de mercado pode ocorrer via transferência de custos dos varejistas a seus fornecedores e não por precificação dos produtos, futuros estudos que busquem identificar o poder de mercado no setor varejista brasileiro poderiam também tentar estimar os custos indiretos transferidos pelos varejistas a seus fornecedores.

\section{Referências bibliográficas}

AGUIAR, D. R. D. Chapter 3: The case of Brazil. In: Stiegert, K. W; Kim, D.H. (editors). Structural changes in food retailing: six country case studies. Madison, WI: Food System Research Group (FSRG), Department of Agricultural and Applied Economics, University of Wisconsin-Madison, FSRG Monograph Series, $\mathrm{n}$ - 22, November 2009.

. A Questão da Transmissão de Preços Agrícolas. Revista de Economia e Sociologia Rural, Brasília, 31(4):291-308, 1993.

; SANTANA, J. A. Asymmetry in farm to retail price transmission: evidence from Brazil. Agribusiness, 18(1):37-48, 2002.

;SILVA, A. L. Changes in beef consumption and retailing competitiveness in Brazil: a rapid appraisal. Agribusiness, 18(2):145-161, 2002.

ARNADE, C.; MUNISAMY, G.; PICK, D. Measuring the degree of retail competition in U.S. cheese markets. Journal of Agricultural \& Food Industrial Organization, Vol. 5: Issue: 1, Article: 1, 2007. Available at: http://www.bepress.com/ jafio/vol5/iss1/art1

BARROS, G. S. A. C. Economia da comercialização agrícola. Piracicaba: FEALQ, 1987.

BRANDT, S. A. Comercialização agrícola. Piracicaba, LIVROCERES LTDA., 1980, $195 \mathrm{p}$.

CLEARY, R. L. O.; LOPEZ, R. A. Is Wal-Mart good for competition? Evidence from milk prices. Food Marketing andPolicy Center, Research Report no 101, October 2007. Available online at http://www.fmpc.uconn.edu.

CUNHA, A. R. A. de A.; MACHADO, M. Quem vende a cesta básica mais barato? (um abalo no mito da eficiência das grandes redes supermercadistas), CEDEPLAR/ FACE/ UFMG, Belo Horizonte, 2003.

FARINA, E. M. M. Q.; NUNES, R. A evolução do sistema agroalimentar e a redução de preços para o consumidor: o efeito de atuação dos grandes compradores. Programa de estudos dos negócios do sistema agroindustrial PENSA, São Paulo: PENSA/FIA/ FEA/USP, 2002. 
GRANGER, C. W. J. Investigating causal relations by econometric models and cross spectral methods. Econometrica, 37(3): 424-38, 1969.

GRIFFITHS, W. E.; HILL, R. C. ; JUDGE, G. G. Learning and practicing econometrics. Singapore, John Willey e Sons, Inc., 866 p., 1993.

GUJARATI, D. N. Econometria básica. São Paulo: Makron Books, 2000. 846 p.

HOUCK, J. P. Na approach to specifying and estimating nonreversible functions. American Journal of Agricultural Economics, 59(3): 570-72, 1977.

IBGE. Pesquisa de orçamentos familiares - POF. www.sidra.ibge.gov.br, 2002.

IEA. Banco de dados. São Paulo, Instituto de Economia Agrícola. Disponível em: http//www.iea.gov.sp.br. (Acesso em 11 de março de 2009).

LASS, D. A. Asymmetric response of retail milk prices in the Northeast revisited. Agribusiness, 21(4): 493-508, 2005.

LERNER, A. P. The concept of monopoly and the measurement of monopoly power. Review of Economic Studies, 1:157-75, June 1934.

LOPEZ, R. A.;LIRÓN-ESPAÑA, C. Social welfare and the oligopoly-efficiency tradeoff in U.S. food processing: a note." Journal of Agricultural E Food Industrial Organization. 1(1), Article 5 (10 pages), 2003. Available from http://www.bepress. com/jafio/voll/iss1/art5.

LOPEZ, R. A., AZZAM, A. A.; LIRÓN-ESPAÑA, C. Market power and/or efficiency: a structural approach. Review of Industrial Organization, 20(March): 115-126, 2002.

LÜTKEPOHL, H..; KRÄTZIG, M. Applied time series econometrics. New York: Cambridge University Press, 323p. 2004.

MARTIN, S. Industrial economics - economic analysis and public policy. $2^{\text {nd }}$ edition, Englewood Cliffs: Prentice Hall, 1993.

MASON, E. S. Price and production policies of large-scale enterprise. American Economic Review, 29:61-74, March 1939.

PHILLIPS, P. C. B. ; PERRON, P. Testing for a unit root in time series regression. Biometrika, 75, 335-346, 1988.

PINDYCK, R. S. ; RUBINFELD, D. L. Econometric models and economic forecasts. $3^{\text {a }}$ ed. Singapore, McGraw-Hill, 596 p., 1991.

SEDDIGHI, H. R.; LAWLER, K. A.; KATOS, A. V. Econometrics: a practical approach. New York: Routledge, 396 p. 2000. 
990 - Poder de Mercado no Varejo Alimentar:

uma análise usando os preços do estado de São Paulo

SHARKEY, T. ; STIEGERT, K. Impacts of nontraditional food retailing supercenters on food price changes. Department of Agricultural and Applied Economics, University of Wisconsin-Madison. FSRG Monograph Series noํ20, 2006.

WOLFRAM, R. Positivistic measures of aggregate supply elasticities: some new approaches- some critical notes. American Journal of Agricultural Economics, 53 (2): 356-59, 1971. 